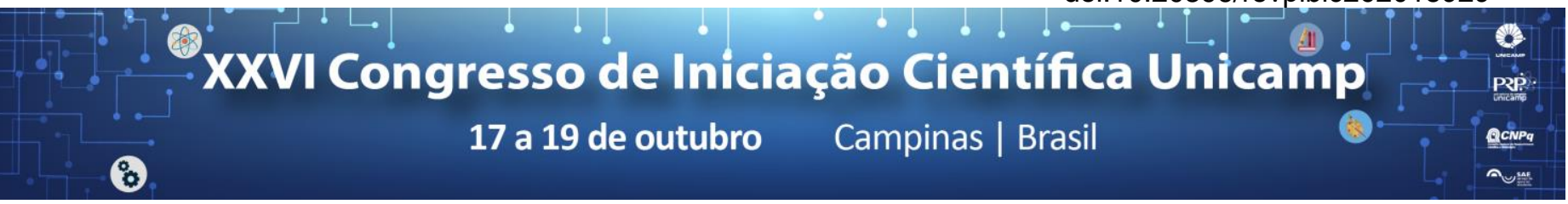

\title{
ANÁLISE CINEMÁTICA TRIDIMENSIONAL DO COMPORTAMENTO DO CENTRO DE MASSA DE ATLETAS DE SLACKLINE.
}

\section{Luiz Eduardo P. de Souza*, Luciano A. Mercadante, Paulo Roberto P. Santiago, Karine J. Sarro.}

\section{Resumo}

O slackline é uma modalidade esportiva que envolve a manutenção do equilíbrio sobre uma estreita fita tencionada entre dois pontos fixos. O objetivo deste estudo foi analisar o comportamento do centro de massa de atletas de slackiline. Atletas foram filmados durante um campeonato de trickline e a posição do centro de massa em função do tempo foi calculada. A descrição do deslocamento do centro de massa trouxe informações sobre a qualidade da execução da manobra.

\section{Palavras-chave:}

Biomecânica, esporte, desempenho.

\section{Introdução}

Slackline é uma modalidade esportiva cujo objetivo é manter-se em equilíbrio sobre uma fita tensionada acima do solo. O estilo trickline é competitivo e o atleta deve fazer manobras acrobáticas sobre a fita, necessitando, portanto, de destreza além de equilíbrio. A análise cinemática do atleta pode trazer informações importantes para melhorar seu desempenho, entretanto, o único trabalho sobre o tema encontrado na literatura avaliou posturas estáticas ${ }^{1}$. Portanto, este trabalho teve como objetivo analisar o comportamento do centro de massa de atletas de trickine durante a manobra buttbounce backflip a partir da análise cinemática tridimensional.

\section{Resultados e Discussão}

Quatro atletas foram filmados por 6 câmeras durante um campeonato de trickline. A partir das imagens, foram obtidas as coordenadas tridimensionais dos ombros, colovelos, punhos, quadris, joelhos, tornozelos, pés e cabeça e foi, então, calculada a posição do centro de massa em função do tempo.

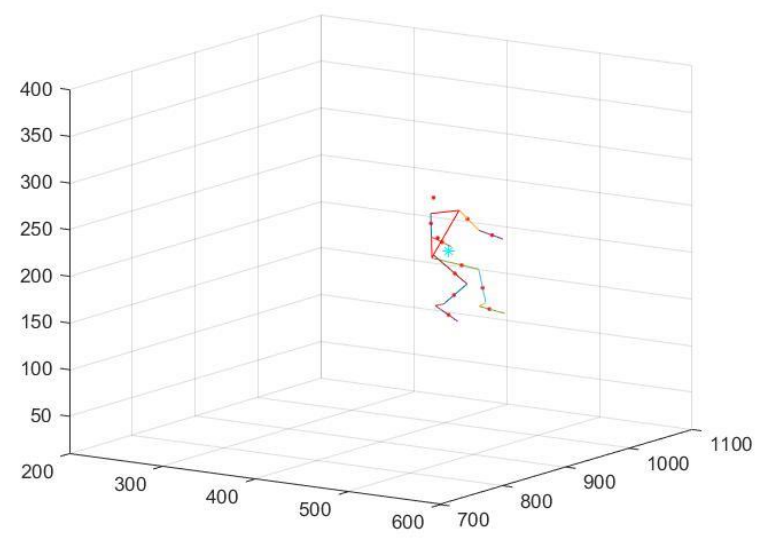

Figura 1. Stick figura obtida a partir das coordenadas tridimensionais das articulações, mostrando o centro de massa de cada segmento (ponto vermelho) e o centro de massa total do corpo (asterisco azul). O instante representado na figura corresponde ao início da manobra.
Tabela 1. Posição do centro de massa (médiatdesvio padrão) e deslocamento máximo (range) nas direções anteroposterior $(X)$, lateral $(Y)$ e vertical $(Z)$.

\begin{tabular}{|c|c|c|c|c|c|c|}
\hline Atleta & $\mathbf{X}$ & $\mathrm{Y}$ & $\mathrm{Z}$ & $\begin{array}{c}\text { Range } \\
\mathbf{X}\end{array}$ & $\begin{array}{c}\text { Range } \\
\mathbf{Y}\end{array}$ & $\begin{array}{c}\text { Range } \\
\mathbf{Z}\end{array}$ \\
\hline 1 & $\begin{array}{c}397.70 \\
( \pm 47.54)\end{array}$ & $\begin{array}{c}950.43 \\
( \pm 10.47)\end{array}$ & $\begin{array}{c}200.90 \\
( \pm 69.50)\end{array}$ & 131.96 & 32.31 & 198.81 \\
\hline 2 & $\begin{array}{c}357.56 \\
( \pm 48.07)\end{array}$ & $\begin{array}{c}954.34 \\
( \pm 11.32)\end{array}$ & $\begin{array}{c}229.92 \\
( \pm 87.45)\end{array}$ & 135.11 & 32.29 & 249.21 \\
\hline 3 & $\begin{array}{c}425.58 \\
( \pm 45.12)\end{array}$ & $\begin{array}{c}941.16 \\
( \pm 11.35)\end{array}$ & $\begin{array}{c}201.12 \\
( \pm 79.93)\end{array}$ & 123.14 & 36.37 & 228.99 \\
\hline 4 & $\begin{array}{c}361.48 \\
( \pm 42.24)\end{array}$ & $\begin{array}{c}947.10 \\
( \pm 7.96)\end{array}$ & $\begin{array}{c}206.55 \\
( \pm 81.06)\end{array}$ & 116.18 & 28.29 & 237.72 \\
& & & & & & \\
\hline
\end{tabular}

Feitas as análises, foi possível constatar que o centro de massa dos sujeitos se localizou na região medial e inferior do tronco, com pequenos deslocamentos no eixo Y (lateral), no qual será importante para a execução completa da manobra sem que o sujeito caia da fita e consequente melhora do desempenho. O deslocamento inicial em Z (vertical) está relacionado ao quanto de energia da fita o atleta acumula para posterior realização da manobra, uma vez que quanto maior for esse deslocamento, relacionado a um deslocamento otimizado com 0 eixo $X$ (anteroposterior), irá resultar num maior alcance da altura da manobra e consequentemente maior tempo e possibilidade de uma melhor execução da manobra.

\section{Conclusões}

As análises feitas podem colobarar com os atletas no reconhecimento mais preciso de possíveis erros e ajustes.

\section{Agradecimentos}

Agradecemos os atletas, a organização do evento e o CNPq.

${ }^{1}$ Mendes, A. M.; Gomes, D. A.; Bello, M. Rev. Corpoconsciência. 2015, 18 , $7-22$. 